\title{
Glutamate Receptor Activity Is Required for Normal Development of Tectal Cell Dendrites In Vivo
}

\author{
Indrani Rajan and Hollis T. Cline \\ Cold Spring Harbor Laboratory, Cold Spring Harbor, New York 11724
}

Glutamatergic retinotectal inputs mediated principally by NMDA receptors can be recorded from optic tectal neurons early during their morphological development in Xenopus tadpoles. As tectal cell dendrites elaborate, retinotectal synaptic responses acquire an AMPA receptor-mediated synaptic component, in addition to the NMDA component. Here, we tested whether glutamatergic activity was required for the elaboration of dendritic arbors in Xenopus optic tectal neurons. In vivo time-lapse imaging of single Dil-labeled neurons shows that the NMDA receptor antagonist APV $(100 \mu \mathrm{M})$ blocked the early development of the tectal cell dendritic arbor, whereas the AMPA receptor antagonist CNQX $(20 \mu \mathrm{M})$ or the sodium channel blocker TTX $(1 \mu \mathrm{M})$ did not. The decreased dendritic development is attributable to failure to add new branches and extend

CNS function depends on the establishment of precise connections between the presynaptic and postsynaptic neurons. Activityindependent and activity-dependent processes operate during the elaboration, pruning, and stabilization of axonal morphology (Goodman and Shatz, 1993; Katz and Shatz, 1996). A comparable role for activity in the development of dendritic arbor structure is not yet clear. Several studies indicate that blocking synaptic activity (Kalb, 1994; Vogel and Prittie, 1995) or sensory deprivation (Weisel and Hubel, 1963; Feng and Rogowski, 1980; Constantine-Paton and Ferrari-Eastman, 1981; Lund et al., 1991) during development can prevent normal elaboration of dendritic arbors. Other studies show that denervation after synapse formation results in dendritic atrophy (Valverde, 1968; Benes et al., 1977; Deitch and Rubel, 1984), supporting a role for afferent activity in maintaining dendritic structure. A third group of studies suggests that dendrites become more elaborate in regions in which afferent inputs have highly correlated patterns of activity (Katz and Constantine-Paton, 1988; Katz et al., 1989; Kossel et al., 1995). Other reports come to the opposite conclusion; blocking NMDA receptors can increase dendritic growth and spine density (Rocha and Sur, 1995; McAllister et al., 1996). Finally, several studies conclude that mechanisms controlling dendritic development are not influenced by synaptic activity (Goodman and Model, 1990; Wong et al., 1991; Dalva et al., 1994; Kossel et al., 1997), although some of the data do show activity-dependent changes in spine density (Wong et al., 1991; Dalva et al., 1994; Kossel et al., 1997).

\footnotetext{
Received January 6, 1998; revised July 16, 1998; accepted July 17, 1998.

This work was supported by the Hoffritz Trust, the National Science Foundation, the National Institutes of Health, and the National Down Syndrome Society. We thank Kim Bronson and Rukhsana Bari for excellent technical support.

Correspondence should be addressed to Hollis Cline, 1 Bungtown Road, Cold Spring Harbor Laboratory, Beckman Building, Cold Spring Harbor, NY 11724. Copyright (C) 1998 Society for Neuroscience $\quad 0270-6474 / 98 / 187836-11 \$ 05.00 / 0$
}

preexisting branches. These observations indicate that NMDAtype glutamatergic activity promotes the initial development of the dendritic arbor. At later stages of tectal neuron development when AMPA receptor-mediated synaptic transmission is strong, both APV and CNQX decrease dendritic arbor branch length, consistent with a role for glutamatergic synaptic transmission in maintaining dendritic arbor structure. These results indicate that AMPA and NMDA receptors can differentially influence dendritic growth at different stages of neuronal development, in correlation with changes in the relative contribution of the receptor subtype to synaptic transmission.

Key words: NMDA receptor; dendrite growth; in vivo imaging; activity-dependent; Xenopus development; retinotectal

In the retinotectal projection of Xenopus tadpoles, images of optic tectal neurons taken over a period of several days in vivo indicate that their morphological development occurs in distinct stages (Wu and Cline, 1998). Newly differentiated stage 1 neurons undergo axonogenesis, with little elaboration of the dendritic arbor. Over the next $24 \mathrm{hr}$, neurons enter stage 2, a period of rapid dendritic arbor growth similar to that seen in zebra fish tectal neurons (Kaethner and Stuermer, 1997). After 3-4 d of rapid dendritic growth, neurons enter stage 3, which is characterized by a slower growth rate and more stable dendritic arbor. The initiation of dendritic growth correlates with retinotectal synaptogenesis. Glutamatergic retinal inputs mediated principally by NMDA-type glutamate receptors (NMDA R) can be recorded from tectal neurons, with few dendritic branches (Wu et al., 1996). As the dendritic arbor elaborates, retinotectal synaptic responses acquire an AMPA receptor (AMPA R)-mediated component, in addition to the NMDA component. Based on these observations, we investigated the potential roles of NMDA- and AMPA-type glutamate receptors in regulating dendritic arbor elaboration. In particular, we tested whether glutamate receptor activity is required for the initiation of dendritic arbor development during the transition from stage 1 to stage 2 and whether the influence of NMDA and AMPA receptor activity on dendritic morphology changes as the relative contribution of the AMPA receptors to synaptic transmission increases. To address this question, we have taken repeated in vivo images of tectal neurons in the presence and absence of activity blockers. We find that NMDA R activity is required for the normal morphological development of young neurons, although both NMDA R and AMPA R play a role in maintaining arbor structure in more mature neurons.

\section{MATERIALS AND METHODS}

Image acquisition. Albino Xenopus laevis tadpoles were reared as described previously (O'Rourke et al., 1994). Single neurons at different 
positions along the rostrocaudal axis of the tectum of stage $46-48$ (Nieuwkoop and Faber, 1956) tadpoles were labeled by 1,1'-dioctadecyl$3,3,3^{\prime}, 3^{\prime}$-tetramethylindocarbocyanine perchlorate (DiI) $(0.01 \%$ in absolute ethanol; Molecular Probes, Eugene, OR) iontophoresis. Positive current (1-10 nA) was applied in 3-10 pulses of $200 \mathrm{msec}$ duration. Animals were screened to select those with single or well isolated brightly labeled neurons. Cells were imaged with a Noran XL laser scanning confocal attachment mounted on an upright Nikon Optiphot, using a $40 \times$ air lens ( $0.8 \mathrm{NA}$; Nikon). Optical sections were collected at $2 \mu \mathrm{m}$ steps through the depth of the neuron. Each optical section was the average of eight frames. Dye injection, screening, and imaging were done in animals anesthetized with $0.02 \%$ 3-aminobenzoic acid ethyl ester (MS222; Sigma, St. Louis, MO) in Steinberg's rearing solution. Animals recovered from anesthetic between imaging sessions.

Stock solutions of activity-blocking drugs APV (Sigma), CNQX (Research Biochemicals, Natick, MA), or TTX (Sigma) were directly added into the rearing solution to final concentrations of $100 \mu \mathrm{M}$ DL-APV, 20 $\mu \mathrm{M}$ CNQX, and $1 \mu \mathrm{M}$ TTX. The first image in all experiments was taken before the animals were exposed to a drug. Animals were returned to the rearing solution containing the drug after each imaging session. For $24 \mathrm{hr}$ drug exposure, the rearing solution was replaced with fresh solution containing the blocker after $12 \mathrm{hr}$. Animals treated with APV showed longer bouts of swimming (Witte, 1995). To quantify the length of a bout of swimming, the behavior was initiated by dropping water into a Petri dish containing a single animal. The swimming was recorded on video tape and analyzed later to measure the time spent swimming for each animal. Analysis was done blind to treatment. CNQX-treated animals appeared to swim less than controls, but this was not quantified. Animals treated with $1 \mu \mathrm{M}$ TTX became immobile after 10-20 min, indicating the penetration of the drug. This concentration blocks sodium-dependent action potentials in retinal axons and tectal neurons (Wu et al., 1996). Light-induced increases in calcium in retinotectal axons are blocked by retinal injections of TTX to yield similar final concentrations (Edwards and Cline, 1997). Exposure of animals to $10 \mu \mathrm{M}$ TTX in the bath killed the animals. Heart beat and blood flow were monitored throughout the experiment to ensure viability of the immobilized animals.

Image analysis. Tectal cell reconstruction and morphometric analysis were performed as described previously for retinal axon arbors (Witte et al., 1996). Cells were reconstructed by tracing the portion of the arbor from each optical section onto an acetate sheet until the entire neuron was drawn. This type of three-dimensional reconstruction provides a more detailed representation of the morphology than the computer generated three-dimensional image, because finer processes visible in the individual optical sections are lost in the computer-generated reconstructions.

The number of branch tips was counted manually. We use "branch tip" to designate the terminal branches in the arbor. Branch tips that were added or retracted over the $4 \mathrm{hr}$ imaging period, as well as the portion of the dendritic arbor which was stable over the imaging period, were identified by superimposing the drawings of the cell from the first and second time points. Total dendritic branch length (TDBL) was measured from scanned drawings of the cells using NIH Image version 1.61. Growth rate was calculated as the change in TDBL between two time points (either 4 or $24 \mathrm{hr}$ ), as stated. Because the data were scanned as two-dimensional drawings and therefore compressed in the $\mathrm{Z}$ dimension, the dendritic branch length measurements underestimate the total branch length. Neurons imaged in this study were on average $30 \mu \mathrm{m}$ in total depth along the $z$-axis, and this parameter did not differ between the experimental groups. Neurons accessible for in vivo imaging are located in dorsal tectum. Because of the shape of the midbrain, most of the neurons located in this region of the tectum have their dendritic arbor oriented toward the lateral edge of the brain, parallel to the dorsal surface of the animal. Consequently, loss of information on the depth of these neurons is minimized compared with neurons, whose cell bodies are located more laterally in the tectum. Data are presented as mean \pm SE. Statistical significance was estimated using the two-tailed $t$ test, after ensuring that the data sets satisfied the criteria of the $F$ test for comparable variances.

\section{RESULTS}

\section{Relationship between morphological dendritic} development and synaptic maturation

We have reported that glutamatergic retinotectal synaptic transmission is initially mediated principally by NMDA receptors in

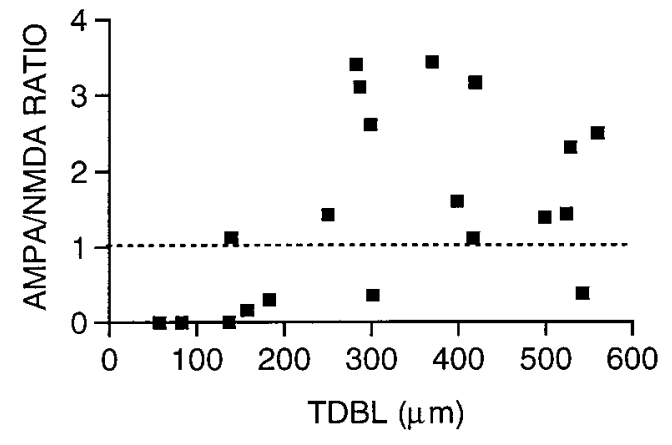

Figure 1. Relationship between dendritic arbor development and glutamatergic synaptic maturation. Neurons with dendritic branch lengths $<200 \mu \mathrm{m}$ have AMPA/NMDA ratios $<1$. Neurons with dendritic branch lengths $>200 \mu \mathrm{m}$ have AMPA/NMDA ratios $>1$.

young neurons. As the neurons and synapses mature, the amplitude of the AMPA component of transmission increases, whereas the amplitude of the NMDA component remains constant (Wu et al., 1996). We have presented previously these data as a correlation between the cell body position along the rostrocaudal axis of the tectum and the AMPA/NMDA ratio. Here, we have replotted these data to show the relationship between AMPA/NMDA ratio and TDBL (Fig. 1). Younger neurons with simple morphologies of TDBL $<200 \mu \mathrm{m}$ have AMPA/NMDA ratios $<1$, whereas more mature complex neurons with TDBL $>200 \mu \mathrm{m}$ have AMPA/NMDA ratios $>1$. Based on these data, we examined the effects of blocking NMDA and AMPA receptors on dendritic arbor development in simple neurons with TDBL $<200$ $\mu \mathrm{m}$ and in more complex neurons with TDBL $>200 \mu \mathrm{m}$.

\section{Glutamate receptor antagonists block dendritic development over $24 \mathrm{hr}$}

To study the effect of glutamate receptor antagonists on initial dendritic arbor development, confocal images through single DiIlabeled optic tectal neurons in albino Xenopus laevis tadpoles were collected over $24 \mathrm{hr}$. Only single well labeled cells with a rostrally projecting axon and simple dendritic arbors at the first time point were included in these experiments. Animals were first imaged and then exposed to either DL-APV $(100 \mu \mathrm{M})$ or CNQX $(20 \mu \mathrm{M})$ in rearing solution for $24 \mathrm{hr}$, after which a second image was taken. The drug and the rearing solution were changed after $12 \mathrm{hr}$. Control animals were returned to normal rearing solution between imaging sessions.

Continuous exposure to APV for $24 \mathrm{hr}$ significantly retards the growth rate of the arbor compared with controls (Figs. 2 and 3), from $260 \pm 39 \mu \mathrm{m} / \mathrm{d}$ in control neurons $(n=16)$ to $158 \pm 18$ $\mu \mathrm{m} / \mathrm{d}$ in neurons exposed to APV $(n=18 ; p<0.05)$. The growth rate in CNQX-treated neurons $(191 \pm 34 \mu \mathrm{m} /$ day; $n=13)$ is not significantly different from controls $(p=0.22)$. These observations indicate that NMDA receptor activity is required for the normal growth of the dendritic arbor in simple neurons.

\section{Rapid effects of glutamate receptor antagonists on dendritic arbor development}

The decreased arbor elaboration seen with $24 \mathrm{hr}$ exposure to APV could be attributable to an increase in branch tip retractions, a decrease in branch tip additions, an increase in branch length retraction, or a decrease in branch length extension. Each of these possibilities connotes a different cellular mechanism. To distinguish these possibilities, we collected images of control and drugtreated neurons at $4 \mathrm{hr}$ intervals. We chose a $4 \mathrm{hr}$ imaging 


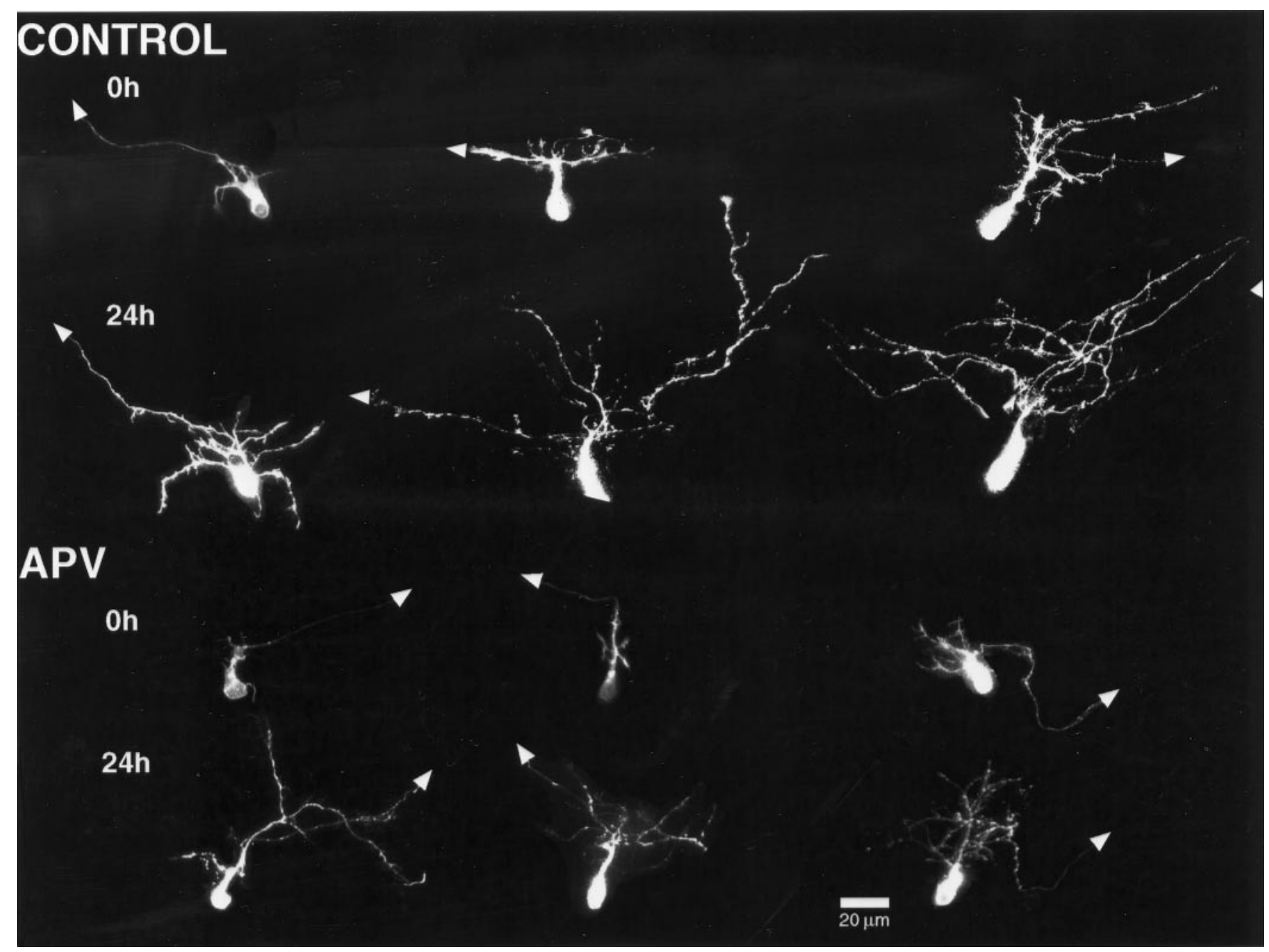

Figure 2. APV slows dendritic arbor growth over $24 \mathrm{hr}$. Time-lapse in vivo confocal images of DiI-labeled tectal neurons imaged at 24 hr intervals. Images in the top row of each set $(0 \mathrm{~h})$ were collected at $0 \mathrm{hr}$, before drug treatment. Images in the bottom row of each set $(24 \mathrm{~h})$ were collected $24 \mathrm{hr}$ after exposure to rearing solution (CONTROL) or APV, as indicated. Three neurons from each group are shown in order of increasing dendritic branch tip numbers at the initial image from left to right.

interval, because this is a long enough period to see quantifiable increases in TDBL and branch tip numbers in control neurons but short enough to be able to follow changes in individual branches with confidence. Animals were first imaged and then exposed to DL-APV $(100 \mu \mathrm{M})$, CNQX $(20 \mu \mathrm{M})$, or TTX $(1 \mu \mathrm{M})$ in rearing solution for $4 \mathrm{hr}$, after which a second image was taken. Control animals were returned to normal rearing solution between imaging sessions.

\section{Matrix of structural changes}

An initial review of the data indicated that a wide range of morphological changes can occur during development. We therefore found it useful to first categorize the types of structural changes that could occur. Figure 4 shows a matrix of possible ways in which the branch length and branch tip number can vary independently of each other to produce dendritic arbors with different morphological features. The prototypical arbor, shown in Figure 4, top, can maintain a constant value for TDBL and still be dynamic (1) by compensatory additions and retractions of branches, (2) by increasing the number of shorter branches so that TDBL does not change significantly, or (3) by decreasing the number of branch tips but lengthening the remaining branch(es).
These possible changes are shown in Figure 4, left column. An increase in TDBL does not necessarily have to result from the addition of new branch tips, as shown in Figure 4, middle column. Extension of existing branches or reduction in the number of branches, along with elongation of the remaining branch(es), can also result in an increase in TDBL. As shown in Figure 4, right column, TDBL can decrease, whereas branch numbers remain constant by shortening preexisting branches. An increase in the number of short branches or a decrease in branch tip numbers can also accompany a decrease in TDBL. Thus, changes in TDBL can occur independently of changes in branch tip number.

\section{Dendritic branch length}

Figures 5 and 6 show images and line drawings, respectively, of neurons imaged at $4 \mathrm{hr}$ intervals under untreated and experimental conditions. For each condition, four neurons are shown in order of increasing arbor complexity in Figures 5 and 6, left to right. In general, control neurons show significant elaboration of the dendritic arbor, even over $4 \mathrm{hr}$. The increase in dendritic arbor structure is a consequence of dynamic changes in the arbor, including branch additions and retractions, as well as both elon- 


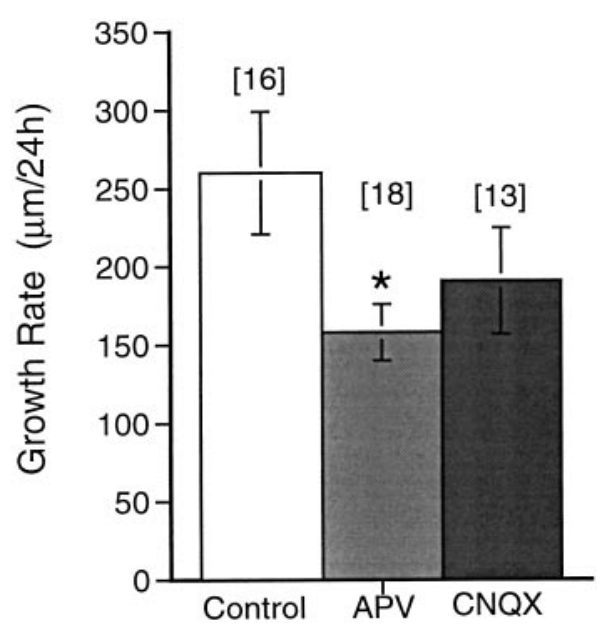

Figure 3. Quantification of the effect of $24 \mathrm{hr}$ APV and CNQX exposure on dendritic growth rate. Increase in TDBL over $24 \mathrm{hr}$ in control, APV-treated, or CNQX-treated neurons. The number of cells observed ( $n)$ under each condition is shown. ${ }^{*} p<0.05$.

gations and shortening of preexisting branch tips. Neurons exposed to APV do not show the normal rate of arbor elaboration.

To provide a quantitative evaluation of the potential role of activity on dendritic arbor development, we analyzed the following parameters: (1) change in growth rate over $4 \mathrm{hr},(2)$ rates of branch tip additions and retractions, and (3) branch length additions and retractions. All groups of cells had comparable branch lengths at the first image (Table 1). Note that tectal neurons do not have spines.

Control neurons $(n=17)$ have an initial TDBL of $109 \pm 13 \mu \mathrm{m}$ and a growth rate of $49 \pm 15 \mu \mathrm{m} / 4 \mathrm{hr}($ Fig. $7 A)$. APV $(n=24)$ significantly decreases dendritic growth rate over $4 \mathrm{hr}(p<0.05)$, whereas TTX and CNQX do not (Fig. 7, Table 1). To illustrate the range in growth rates within the group of neurons imaged, we graphed the changes in TDBL for each neuron in the four treatment conditions over the $4 \mathrm{hr}$ period (Fig. 7B). Control neurons of similar initial arbor sizes can increase or decrease TDBL or show no detectable change in TDBL over $4 \mathrm{hr}$. No APV-treated neuron showed the large TDBL increases seen in control neurons. This suggests that the drug selectively affected neurons that were in the rapid growth phase of dendritic development. CNQX- and TTX-treated neurons exhibited a range of growth rates comparable with control neurons. To test whether the effect of APV on dendritic growth was reversible, a subset of neurons imaged after $4 \mathrm{hr}$ exposure to APV were replaced in normal rearing bath and imaged again the next day. These neurons had a growth rate of $105 \pm 20 \mu \mathrm{m} / 24 \mathrm{hr}(n=12)$, indicating recovery of dendritic growth.

\section{Branch tip dynamics}

The slower dendritic growth rate seen in the presence of APV could be attributable to an increased rate of branch tip retractions, a decreased rate of branch tip additions, or both. To address this issue, we examined rates of branch tip additions and retractions over $4 \mathrm{hr}$. Control neurons added an average of $3.9 \pm 1.3$ branch tips and retracted an average of $1.2 \pm 0.4$ branch tips over $4 \mathrm{hr}$ (Fig. 7C,D). APV significantly decreased branch additions $(p<0.05)$. Neither TTX nor CNQX significantly changed branch tip additions or retractions. To demonstrate the range of changes in branch tip numbers in the groups of neurons studies,

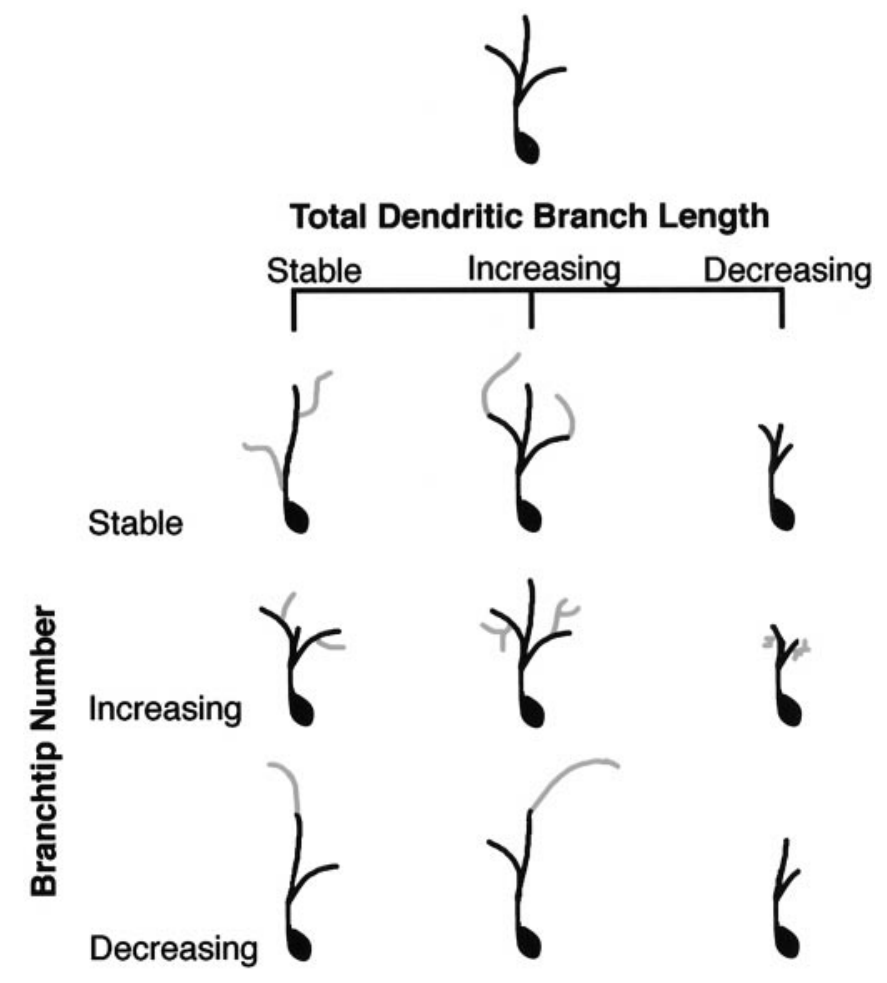

Figure 4. Matrix of changes in dendritic arbor morphology as a function of branch dynamics. A prototypical neuron is shown at the top. Possible changes in TDBL are shown from left to right and branch tip number from top to bottom. Neuronal morphology can change from the prototype, without any apparent change in branch tip number or branch length or by increasing or decreasing branch length, branch tip number, or both.

we have graphed changes in branch tip numbers for the individual neurons under each condition, as shown in Figure $7 E$. As with changes in TDBL, control neurons are heterogeneous with respect to changes in branch tip numbers over $4 \mathrm{hr}$. This analysis indicates that a decreased rate of branch tip additions contributes to the decreased elaboration of the dendritic arbor seen with APV.

\section{Arbor stability}

The decreased growth rate seen with APV could also be attributable to a change in the rates of extension or retraction of preexisting branches. To determine whether the activity blockers alter the relative lengths of the arbor that are stable or dynamic over the $4 \mathrm{hr}$ period, we superimposed drawings (Fig. 8) of the initial and $4 \mathrm{hr}$ images and color coded the dendrites to show stable portions of the arbor in black, branch length extensions and branch tip additions in green, and branch length or branch tip retractions in red.

The stable portion of the arbor over the $4 \mathrm{hr}$ period (Fig. 8, black) is comparable for all four groups of neurons (Table 1). APV significantly decreased the dendritic branch extension over $4 \mathrm{hr}$ (Fig. 8, green), from $94 \pm 15 \mu \mathrm{m}$ in controls to $40 \pm 6 \mu \mathrm{m}$ in APV-treated neurons $(p<0.001)$ (Fig. 9A). APV does not alter branch length retraction (Figs. 8, red, 9B). CNQX and TTX do not alter arbor stability (Fig. 9). This analysis indicates that NMDA R activity is required for extension of branches. Failure to elongate branches in APV contributes to the decreased growth rate in APV-treated neurons. 


\section{CONTROL}

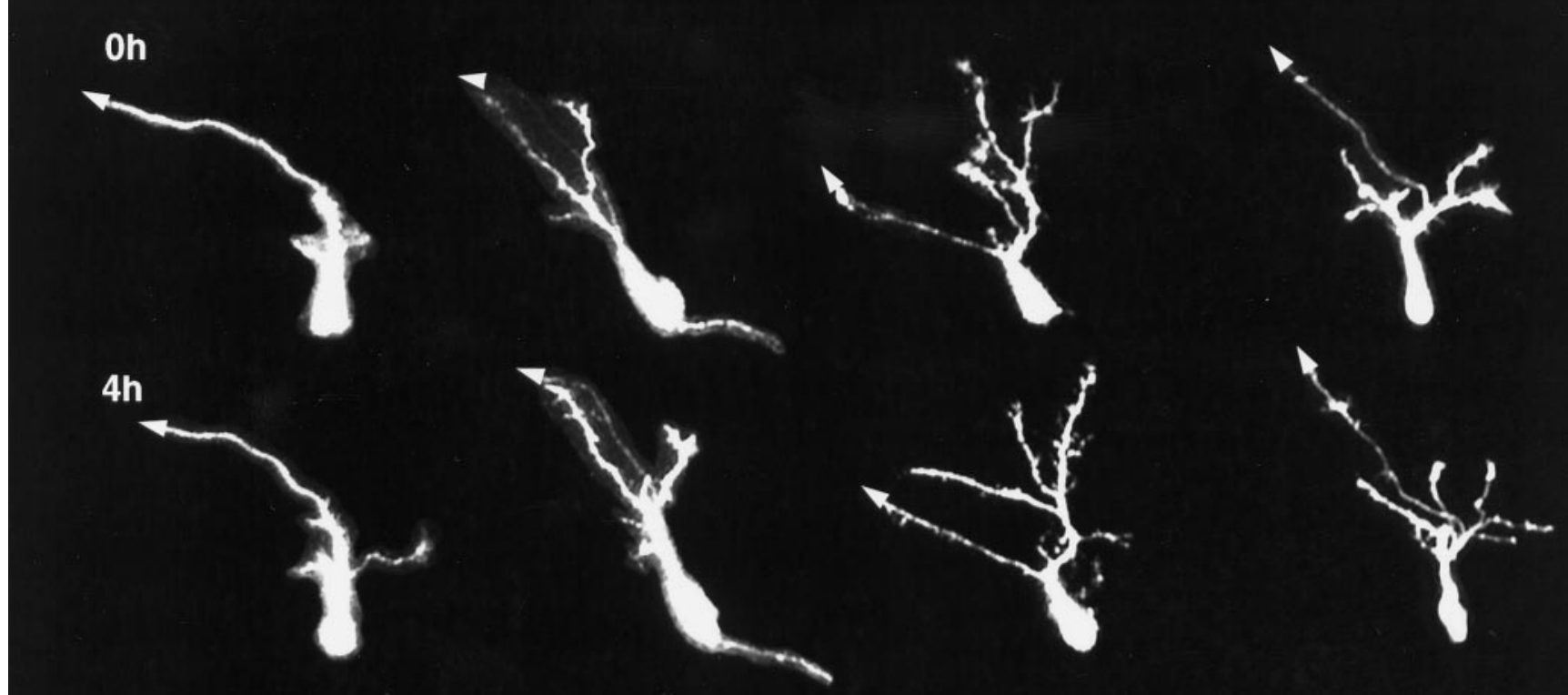

\section{APV}

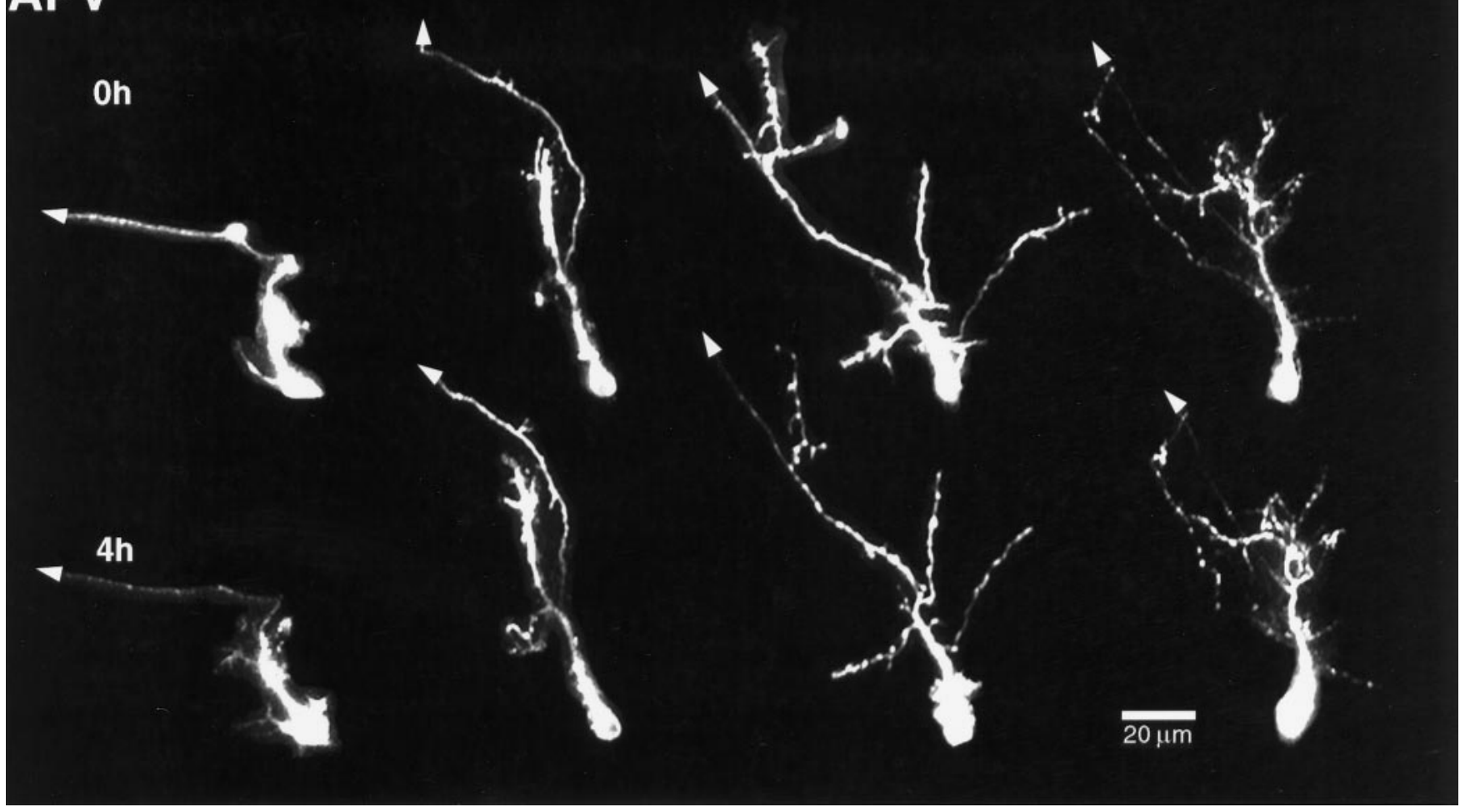

Figure 5. APV blocks dendritic arbor growth over $4 \mathrm{hr}$ in vivo. Time-lapse in vivo confocal images of DiI-labeled tectal neurons imaged at 4 hr intervals. Four cells are shown in order of increasing dendritic branch tip number at the first image from left to right. The top row of each set (Oh) of images was collected at the beginning of the experiment before drug treatment. The bottom row of each set $(4 h)$ of images was collected after $4 \mathrm{hr}$ in rearing solution $(C O N T R O L)$ or $100 \mu \mathrm{M}$ APV.

\section{Glutamatergic synaptic activity maintains arbor structure in complex neurons}

To determine whether the robust effect of APV on dendritic dynamics is specific to the young neurons when the relative contribution of NMDA R activity to retinotectal synaptic transmission is high, we tested the effect of APV and CNQX treatment on dendritic arbor dynamics in more mature tectal neurons with
AMPA/NMDA ratios $>1$. Tectal neurons with $\mathrm{TDBL}>200 \mu \mathrm{m}$ (Table 2) were exposed to either APV or CNQX for $4 \mathrm{hr}$ (Fig. 10). Growth rates and changes in rates of branch tip additions and retractions were compared with control tectal neurons of similar dendritic arbor complexity. In contrast to simpler neurons, more complex mature neurons are significantly affected by exposure to both CNQX and APV. 


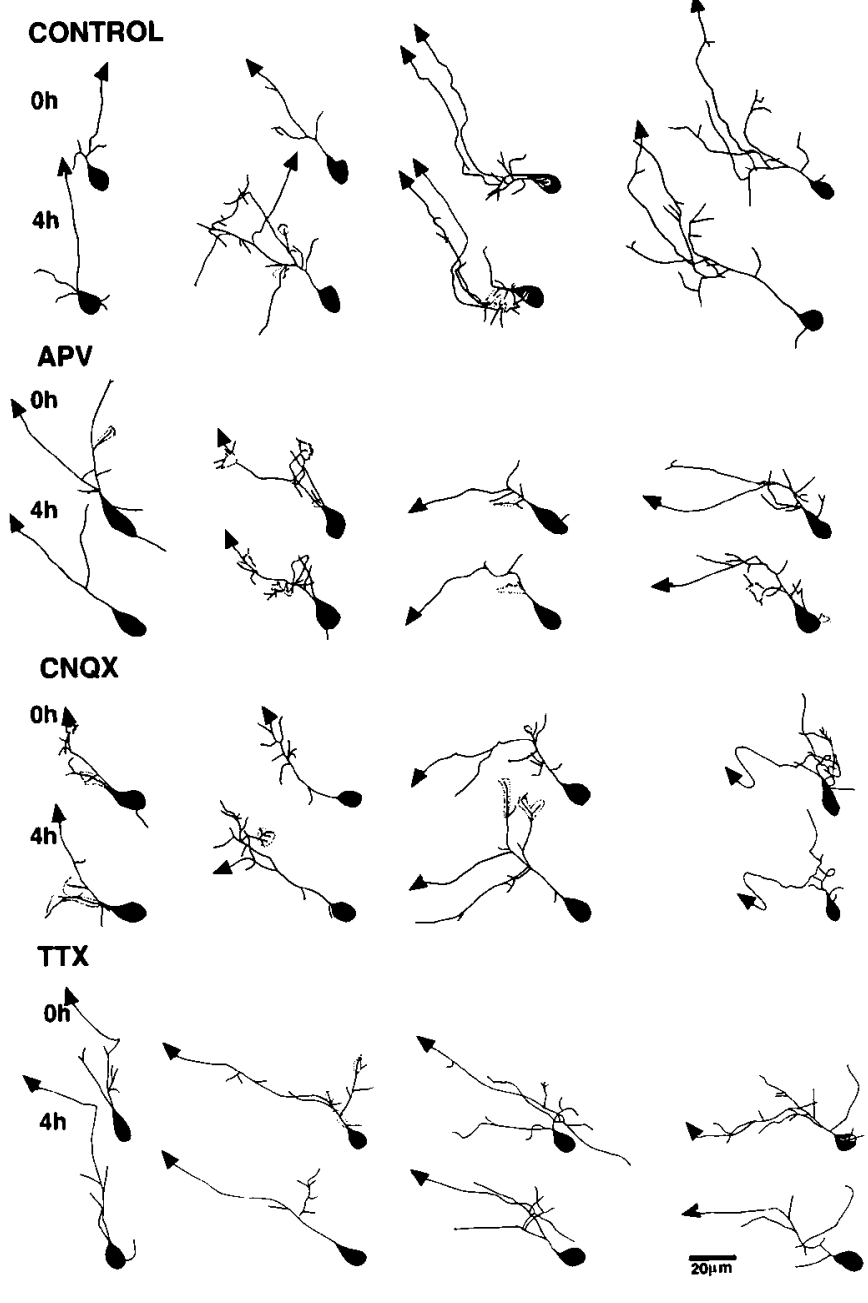

Figure 6. NMDA receptor blockade slows dendritic arbor development in simple neurons. Time-lapse in vivo confocal images of four DiI-labeled tectal neurons from control animals or animals exposed to $100 \mu \mathrm{M} \mathrm{APV}$, $20 \mu \mathrm{M}$ CNQX, or $1 \mu \mathrm{M}$ TTX. Images in the top row of each set $(0 h)$ were collected before drug treatment. Images in the bottom row of each set $(4 \mathrm{~h})$ were collected after $4 \mathrm{hr}$ in rearing solution (CONTROL) or drug solution, as indicated. Control neurons show increases in branch length and dynamic changes in the branch tip numbers and arrangement. Cells from the treated animals show only modest morphological changes. Growth cones are represented by dotted outlines.

The growth rate of control complex tectal neurons is $34 \pm 15$ $\mu \mathrm{m} / 4 \mathrm{hr}$ (Fig. 11, Table 2). APV and CNQX significantly decrease growth rates in complex neurons over $4 \mathrm{hr}$ (Fig. 11A). Neither APV nor CNQX significantly altered rates of branch additions or retractions. These data indicate that both NMDA R and AMPA $\mathrm{R}$ contribute to dendritic arbor growth in more complex neurons. The net decrease in TDBL in these neurons also indicates that glutamatergic synaptic activity is required to maintain dendritic structure.

Although growth rates for simple and more complex neurons average $46 \pm 13 \mu \mathrm{m} / 4 \mathrm{hr}$ and $34 \pm 15 \mu \mathrm{m} / 4 \mathrm{hr}$, respectively, when growth rates are normalized to the initial TDBL, it is clear that simple neurons have a greater relative growth rate than complex neurons ( $66 \pm 22$ and $10 \pm 3 \%$, respectively). Blocking NMDA R has a greater effect on the growth rate of simple neurons compared with complex neurons (Fig. 11B). Such an effect is not seen with CNQX (data not shown).

\section{Summary of tectal cell dynamics}

Our data indicate that NMDA and AMPA receptors play different roles in controlling dendritic arbor structure at different stages of neuronal development. Early in development when glutamatergic transmission is mediated principally by NMDA R, these receptors are required for the initial elaboration of the dendritic arbor. Blocking NMDA R prevents dendritic arbor growth by decreasing new branch additions and branch extensions. These parameters are unaffected by blocking AMPA R or voltagedependent $\mathrm{Na}^{+}$channels. At later stages of development when the AMPA R contribution to synaptic transmission is greater, both AMPA R and NMDA $\mathrm{R}$ are required to maintain normal growth rate and arbor complexity (Fig. 12). The effect of CNQX and APV on more mature neurons is not attributable to a significant change in branch tip dynamics but could be attributable to a change in branch length extension, which is technically difficult to resolve in these neurons.

\section{DISCUSSION}

Images collected at daily intervals over periods up to $6 \mathrm{~d}$ show the overall pattern of dendritic arbor development in tectal neurons (Wu and Cline, 1998). Here, we imaged optic tectal neurons over a $4 \mathrm{hr}$ interval to examine the effect of glutamate receptor blockers on the dynamics of dendritic arbor elaboration at different points during neuronal development. As neurons develop a more complex dendritic arbor, predominantly NMDA R-mediated glutamatergic synapses acquire AMPA R responses. We divided the population of imaged neurons into two groups, "simple" and "complex", based on electrophysiological data showing that simple neurons with TDBL $<200 \mu \mathrm{m}$ have an AMPA/NMDA ratio $<1$, whereas complex neurons with TDBL $>200 \mu \mathrm{m}$ have an AMPA/NMDA ratio $>1$. We exposed neurons to APV and CNQX to test the relative role of AMPA R and NMDA R in dendritic arbor growth. We find that dendritic growth in simple neurons is selectively blocked by APV, supporting a strong role for NMDA $\mathrm{R}$ in the initiation of dendritic arbor development. The data also suggest that NMDA R activity is specifically linked to mechanisms controlling dendritic arbor growth and dynamics. Although dendritic growth is more modest in complex neurons, both AMPA R and NMDA R activity are required to maintain dendritic growth rate and arbor structure in complex neurons. Thus, the role of synaptic activity on dendritic arbor morphology changes with development.

\section{Dynamics of dendritic arbor growth under normal conditions}

Images of simple neurons collected over a $4 \mathrm{hr}$ interval show an average net increase in both branch tip number and TDBL, attributable to a relatively greater rate of branch tip additions compared with retractions and to relatively greater branch length extensions compared with retractions. We find that neurons that appear morphologically similar at the first image are quite heterogeneous in their growth rates over the $4 \mathrm{hr}$ period. Neurons can show net increases, net decreases, or no net change in branch tip numbers or TDBL over $4 \mathrm{hr}$. It is important to point out that neurons that show no changes in these morphometric parameters over $4 \mathrm{hr}$ can still exhibit considerable branch dynamics, as documented for the neurons imaged at $30 \mathrm{~min}$ intervals over $2 \mathrm{hr}$ (Rajan et al., 1998). For the population of simple neurons we imaged, growth rate did not correlate with TDBL or the number of branch tips at the first image (Fig. 7). Nevertheless, simple neurons imaged over $24 \mathrm{hr}$ do show a net growth of the dendritic 


\begin{tabular}{llllll}
\hline Table 1. Dendritic arbor parameters in control and drug-treated simple neurons over $\mathbf{4}$ hr \\
& TDBL $(\mu \mathrm{m})$ & $\begin{array}{l}\text { TDBL }(\mu \mathrm{m}) \\
\text { Treatment }\end{array}$ & $\begin{array}{l}\text { Branch tips } \\
0 \mathrm{hr}\end{array}$ & $\begin{array}{l}\text { Branch tips } \\
4 \mathrm{hr}\end{array}$ & $\begin{array}{l}\text { Stable branch } \\
\text { length }(\mu \mathrm{m})\end{array}$ \\
\hline Control $(n=17)$ & $109 \pm 13$ & $158 \pm 20$ & $9.1 \pm 1$ & $11.8 \pm 1.9$ & $69 \pm 9$ \\
APV 100 $\mu \mathrm{M}(n=24)$ & $102 \pm 10$ & $92 \pm 8^{* * *}$ & $7.1 \pm 0.7$ & $6.2 \pm 0.8^{* * *}$ & $69 \pm 9$ \\
CNQX 20 $\mu \mathrm{M}(n=17)$ & $117 \pm 12$ & $159 \pm 28$ & $6.3 \pm 0.7$ & $7.8 \pm 1.2$ & $69 \pm 6$ \\
TTX 1 $\mu \mathrm{M}(n=30)$ & $113 \pm 9$ & $133 \pm 12$ & $9.0 \pm 0.7$ & $8.9 \pm 1.1$ & $66 \pm 7$
\end{tabular}

${ }^{* * *} p<0.01$ relative to control value.

A

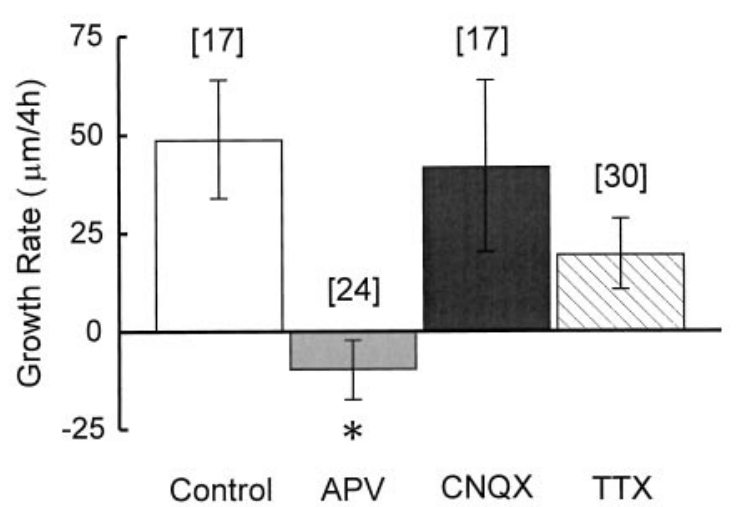

C

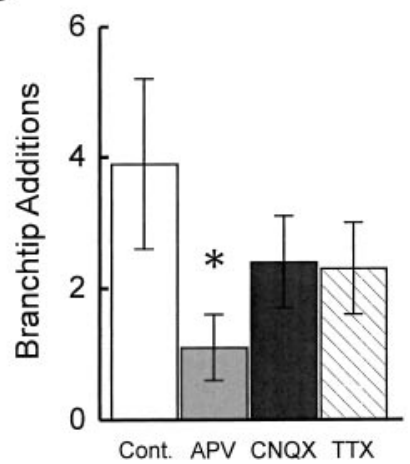

D

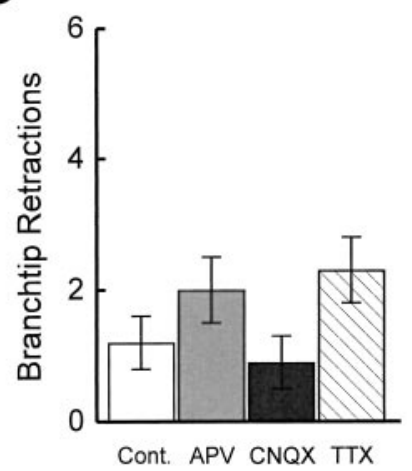

B
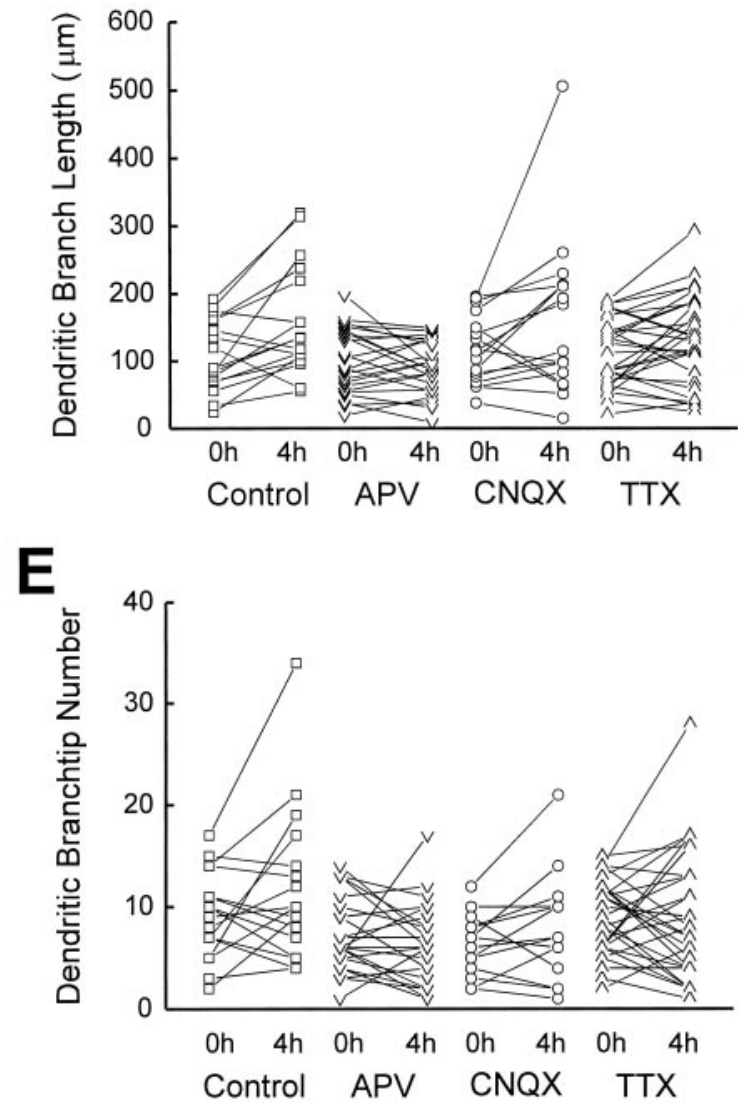

Figure 7. Quantification of effect of activity blockade on dendritic arbor development. $A$, Growth rate over 4 hr in control cells and cells from animals exposed to APV, CNQX, or TTX. Number of cells observed $(n)$ for each condition in $A$ also applies to $C$ and $D$. $B$, Scatterplots of changes in dendritic branch length for each neuron under the four conditions. Rate of branch tip additions $(C)$ and retractions $(D)$ for control and drug-treated neurons over $4 \mathrm{hr} . E$, Scatterplots of changes in dendritic branch tip number for each neuron under the four conditions. ${ }^{*} p<0.05$.

arbor. More complex neurons have a slower growth rate, as shown previously (Wu and Cline, 1998), at least partially attributable to a lower rate of branch dynamics.

It is possible that the population of tectal cells we have imaged is heterogeneous. If different tectal cell types have different growth rates, then this could contribute to the heterogeneity in growth rates we observed. Multiple tectal cell types have been identified in frogs according to morphological and electrophysiological criteria (Potter, 1969; Lázár, 1973; Matsumoto and Bando, 1980; Katz and Constantine-Paton, 1988). However, we have not labeled all these previously identified cell types in young Xenopus tadpoles. All of the neurons we included in this analysis have a rostrally directed efferent axon. Even so, rostrally projecting neurons may include several subsets of cell types, which we have not been able to distinguish based on morphological criteria.

\section{Glutamatergic synaptic activity and dendritic arbor dynamics}

Blocking NMDA R early in the period of dendritic arbor development prevented the initial elaboration of the arbor, whereas blocking AMPA R during this period had no significant effect on arbor morphology. The differential effects of blocking NMDA R and AMPA R may reflect the relative preponderance of NMDA R-mediated synaptic transmission compared with AMPA $\mathrm{R}$-mediated synaptic transmission in young neurons (Wu et al., 1996), the postulated neurotrophic role for extrasynaptic NMDA receptors in newly differentiated neurons (Blanton et al., 1990; LoTurco et al., 1991), as well as the developmentally regulated change in subunit composition of the NMDA R in developing neurons (Monyer et al., 1992). NMDA receptor-mediated cur- 
CONTROL
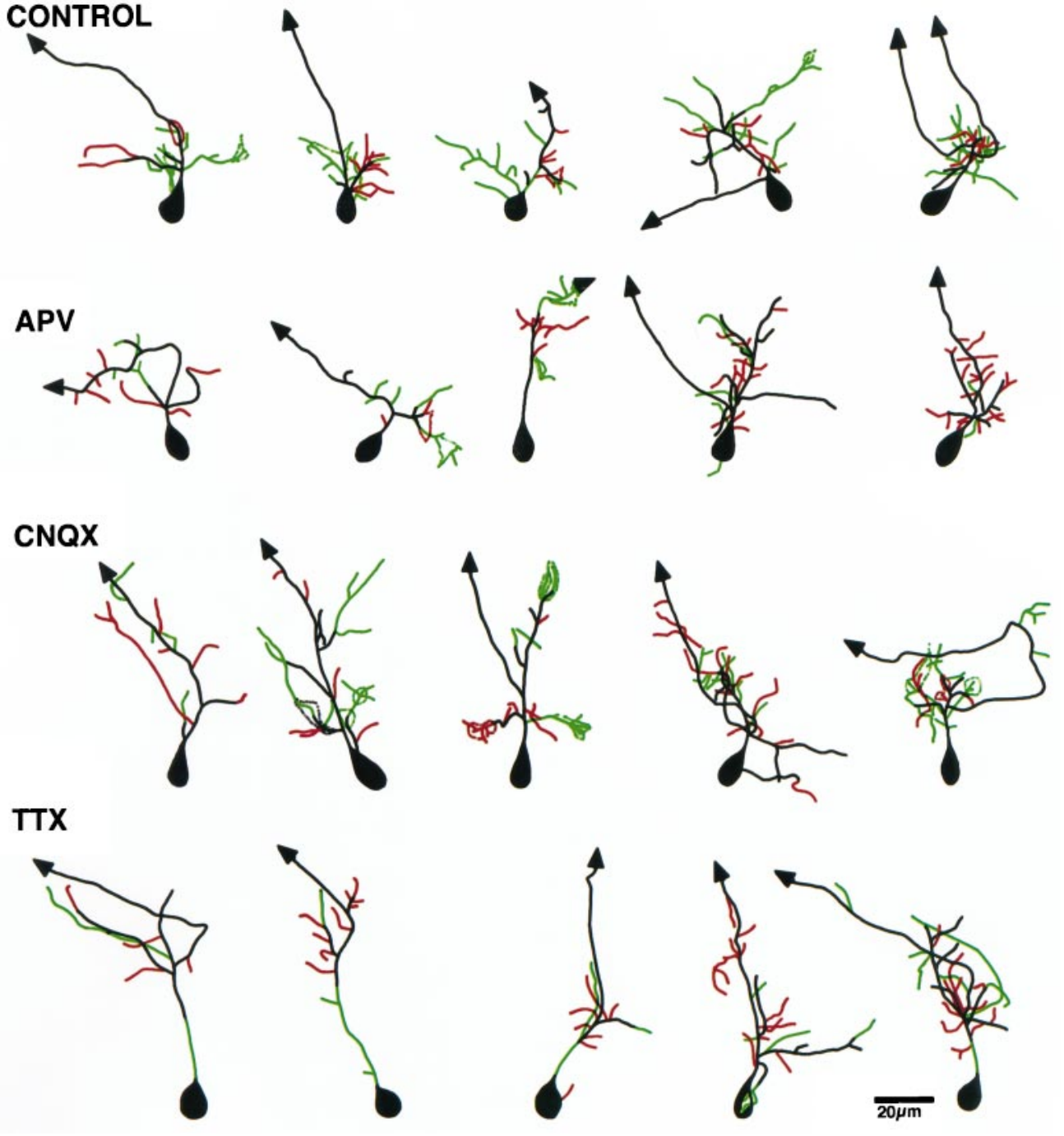

Figure 8. Color-coded drawings reveal arbor dynamics. Composite line drawings were obtained by superimposing the drawings from the $4 \mathrm{hr}$ time point onto the $0 \mathrm{hr}$ time point. The stable branches of the arbor are shown in black, branch additions and extensions in green, and branch retractions in red. Control neurons show more branch length additions compared with retractions. APV-treated neurons show fewer additions than controls.
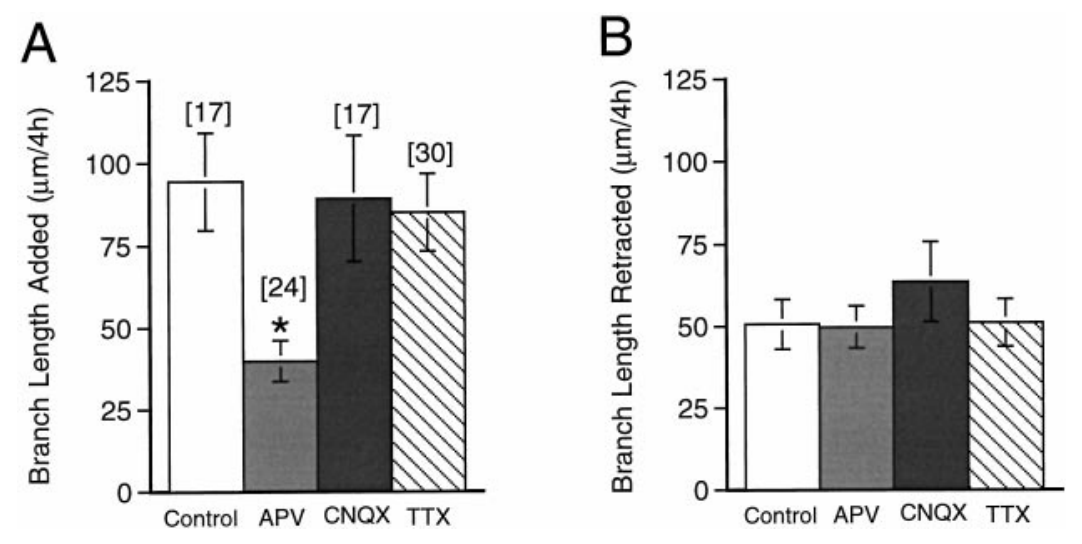

Figure 9. APV selectively decreases branch extension. Dendritic branch length increase $(A)$ and decrease $(B)$ of the arbor for control and drug-treated neurons. Numbers of cells $(n)$ for each condition are shown above the bar in $A$. ${ }^{*} p<0.001$.

rents in neurons from caudal tectum have slower decay kinetics than more mature neurons (Cline et al., 1997). The prolonged calcium influx via these receptors could result in significantly greater changes in intracellular calcium concentration than might result indirectly from AMPA receptor-mediated depolarization. It is likely that the spatial and temporal changes in intracellular calcium concentrations directly regulate the cellular mechanisms controlling cytoskeletal stability and branch dynamics (Lankford et al., 1996). As neurons mature, their dendritic structure be- comes less dynamic, and their AMPA R-mediated synaptic transmission increases. Consistent with this shift in AMPA/NMDA ratio, CNQX has a greater effect on dendritic morphology as neurons mature.

It is interesting to note that APV can alter branch dynamics and branch length extensions, whereas TTX has no detectable influence on these parameters. Such a selective influence of NMDA R activity on neurite outgrowth has also been reported in cultured Xenopus tectal neurons (Lin and Constantine-Paton, 


\begin{tabular}{lllll}
\hline Table 2. Dendritic arbor parameters in control and drug-treated complex neurons over $4 \mathbf{~ h r}$ \\
Treatment & TDBL $(\mu \mathrm{m}) 0 \mathrm{hr}$ & TDBL $(\mu \mathrm{m}) 4 \mathrm{hr}$ & Branch tips 0 hr & Branch tips 4 hr \\
\hline Control $(n=20)$ & $346 \pm 29$ & $379 \pm 36$ & $25.9 \pm 3.7$ & $27.3 \pm 3.8$ \\
APV 100 $\mu \mathrm{M}(n=18)$ & $398 \pm 39$ & $383 \pm 43$ & $28 \pm 2.3$ & $23.2 \pm 2$ \\
CNQX 20 $\mu \mathrm{M}(n=18)$ & $400 \pm 28$ & $376 \pm 33$ & $22.6 \pm 1.6$ & $22.3 \pm 2.1$ \\
\hline
\end{tabular}
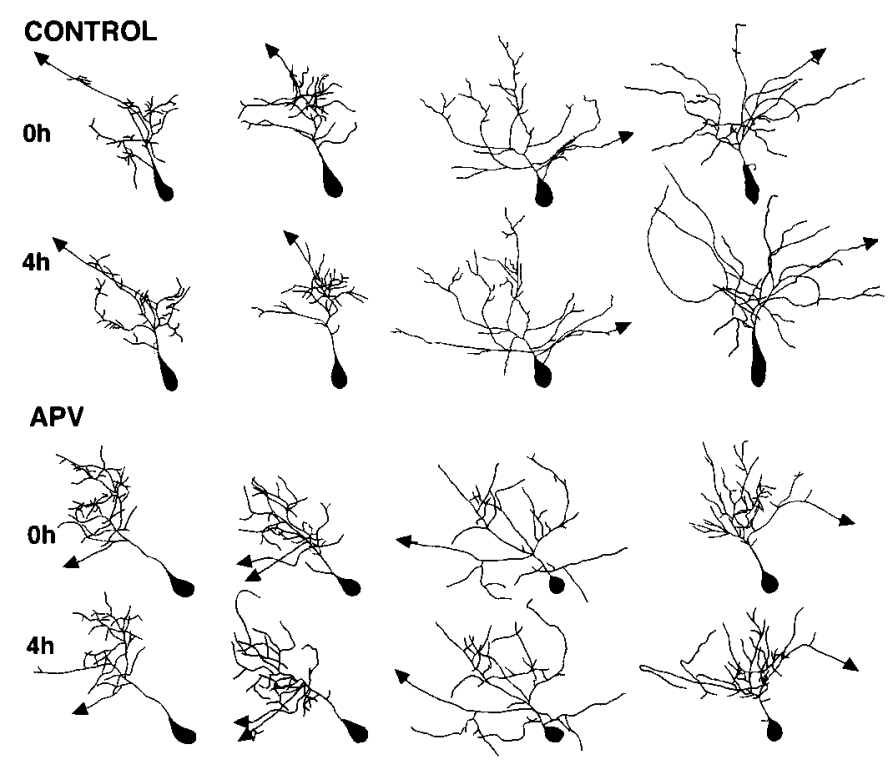

CNQX
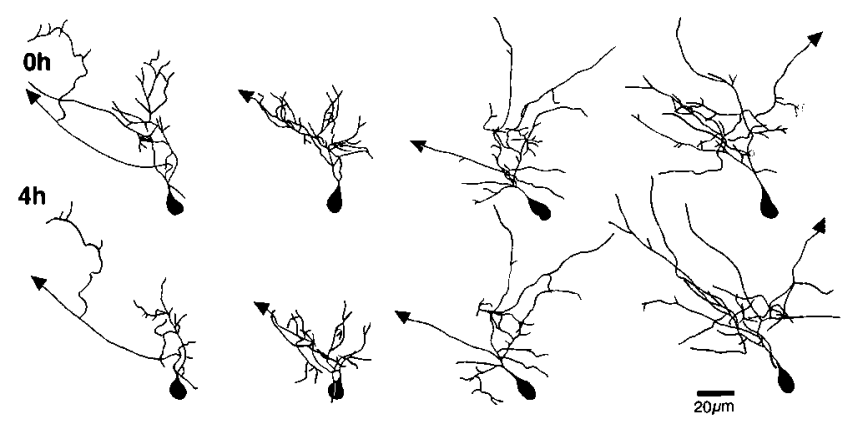

Figure 10. APV and CNQX slow dendritic arbor development in more complex neurons. Time-lapse in vivo confocal images of four DiI-labeled tectal neurons from either control animals or animals exposed to $100 \mu \mathrm{M}$ APV or $20 \mu \mathrm{M}$ CNQX. Images in the top row of each set $(0 h)$ were collected before drug treatment. Images in the bottom row of each set (4h) were collected after $4 \mathrm{hr}$ in rearing solution (Control) or drug solution, as indicated. Control neurons show modest increases in branch length and branch tip numbers and arrangement. Cells from APV- and CNQXtreated animals show decreased morphological changes. Growth cones are represented by dotted outlines.

1998). These data indicate that NMDA R activity can influence dendritic arbor development independently of the generation of sodium-dependent action potentials in tectal neurons. This could occur by activation of nonsynaptic NMDA R or by synaptic inputs that are subthresholds for firing sodium-dependent action potentials. This result also raises the issue of the source of glutamate to activate NMDA R when afferent activity is blocked by TTX. One potential source is from spontaneous release of transmitter, which occurs in the presence of TTX. The relatively high affinity of NMDA R for glutamate in developing tissue (Kutsewada et al., 1992), as well as the delayed expression of glutamate transporters
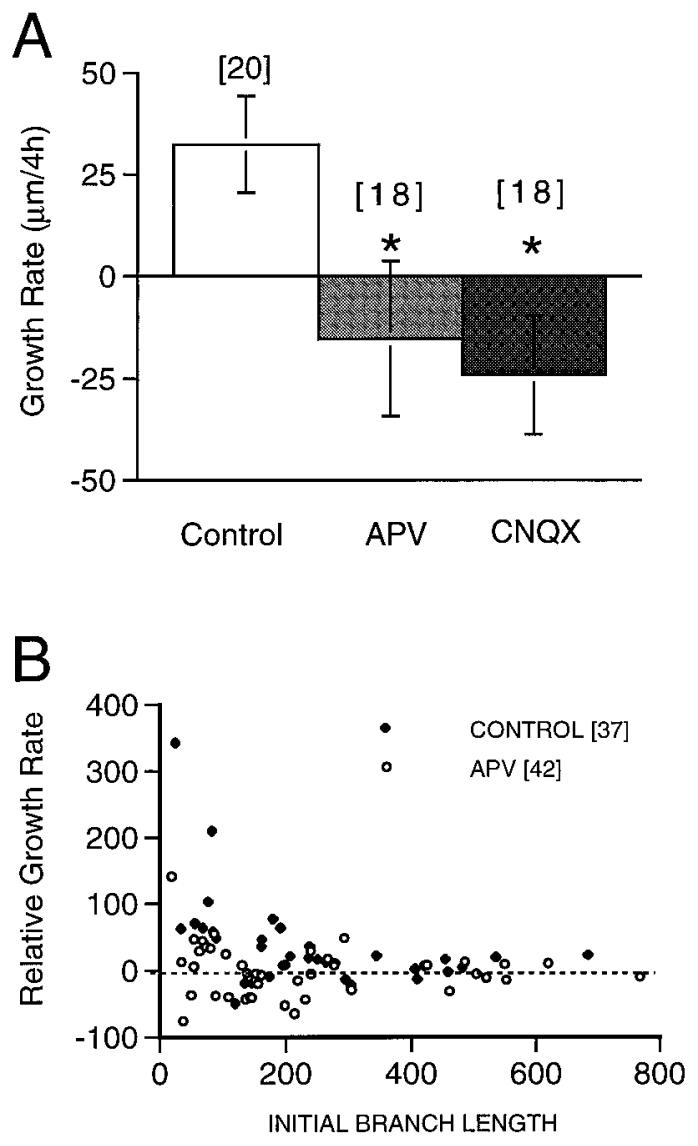

Figure 11. NMDA R and AMPA R maintain dendritic arbor structure in complex neurons. $A$, Growth rate over $4 \mathrm{hr}$ in complex neurons from control animals and those exposed to APV or CNQX. Numbers of cells observed $(n)$ for each condition are shown above the corresponding bars. Growth rates of each APV and control neuron $(B)$ normalized to its initial TDBL. Simple cells show relatively greater growth rates than complex cells. Note that APV-treated neurons with TDBL $<200 \mu \mathrm{m}$ show lower growth rates than control cells. ${ }^{*} p<0.05$.

during development (Ullensvang et al., 1997), provide the conditions for low levels of spontaneously released glutamate to activate NMDA R, even in the absence of action potential activity.

Because the drugs were added to the rearing solution, the results do not differentiate between the effects of blocking activity at retinotectal synapses, intertectal, intratectal, and other connections or retrograde information because of the tectal axon activity or the effect of extrasynaptic glutamatergic receptors on dendritic development.

\section{Significance of arbor dynamics on the functional morphology}

One open issue in developmental neuroscience concerns the reproducible acquisition of morphological type. Based on cell culture work, it seems that different neurons have intrinsic pro- 

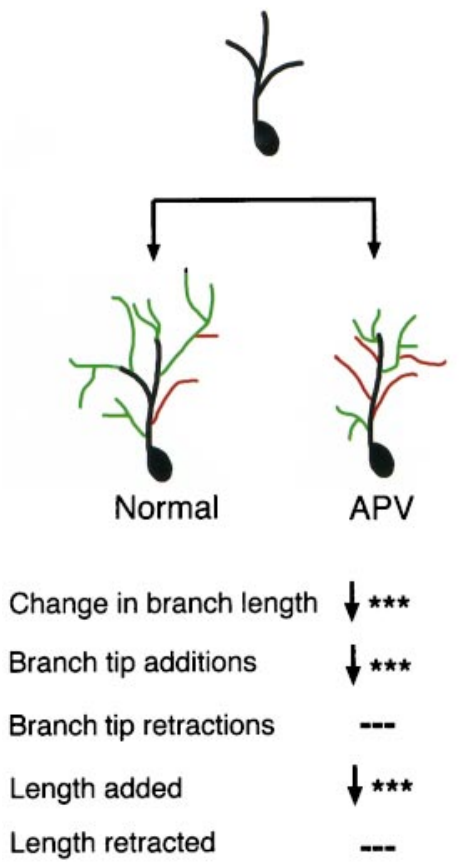

grams to regulate neuronal structure (Mattson, 1988). The present experiments, as well as previous reports from rodent spinal cord motoneurons (Kalb, 1994) and in chick Purkinje cells (Vogel and Prittie, 1995), indicate that synaptic activity can shape dendritic structure in vivo.

Our data support the following model of the control of dendritic growth. Glutamatergic synaptic activity, one source of which is the retina, promotes the initial development of the dendritic arbor by increasing rates of branch tip additions and increasing elongation of existing branch tips. Once the dendritic arbor has formed, synaptic activity is required to stabilize and maintain dendritic arbor structure, consistent with previous studies demonstrating that the loss of afferent activity leads to dendritic atrophy (Valverde, 1968; Benes et al., 1977; Deitch and Rubel, 1984). During the phase of rapid dendritic growth, a local decrease in excitatory input to developing tectal cell dendrites may reduce local dendritic elaboration, whereas a local increase in afferent activity may promote local growth. The decreased branch elongation in APV-treated simple neurons indicates that synaptic inputs onto major branch tips of the dendritic arbor stabilize those structures and are required to maintain branch length. Our data also suggest that synaptic inputs can increase the stability of the rapidly growing dendritic arbor by decreasing rates of branch tip retractions in young neurons.

Such a developmental influence of synaptic inputs on dendritic arbor development may underlie the rostrocaudal bias in the dendritic arbor of tectal neurons and the preference to arborize in eye-specific stripes observed in postmetamorphic froglets (Katz and Constantine-Paton, 1988), as well as in cat cortex (Kossel et al., 1995), stratification of retinal ganglion cell dendrites (Bodnarenko and Chalupa, 1993), the selective pruning of dendritic branch tips seen in cortical layer 5 pyramidal neurons (Koester and O’Leary, 1992), and oriented dendritic elaboration in barrel cortical neurons (Harris and Woolsey, 1981). Time-lapse images of dendritic spine dynamics in hippocampal pyramidal neurons from cultured slices also support a model in which synaptic inputs stabilize spines during a period of synaptogenesis (Dailey and Smith, 1996; Ziv and Smith, 1996).

The heterogeneity in rates of dendritic development observed in untreated simple neurons may reflect differences in the strengths of synaptic inputs. Perhaps the neurons that appeared relatively stable over the $4 \mathrm{hr}$ period we have imaged had relatively little correlated input, whereas other neurons that exhibited considerable growth over the same period had received highly correlated inputs. This idea is supported by the observation that the variance of growth rates in APV-treated simple neurons is relatively small.

We have shown previously that blocking NMDA R disrupts the topographic organization of the retinotectal axon projection (Cline et al., 1987; Cline and Constantine-Paton, 1989) and that blocking tectal cell activity increases arbor dynamics in the presynaptic retinotectal axons (O'Rourke et al., 1994). These studies and others (Scherer and Udin, 1989; Schmidt, 1990; Schmidt and Buzzard, 1993) suggest a retrograde effect of retinotectal synaptic activity on axon arbor stabilization. Consistent with this, a recent report indicates that NMDA $\mathrm{R}$ blockade promotes neurite sprouting and the expression of presynaptic markers in cultured Xenopus neurons (Lin and Constantine-Paton, 1998). In contrast, we find that blocking NMDA $\mathrm{R}$ decreases rates of branch additions to the postsynaptic dendritic arbor over the short term and severely attenuates dendritic arbor growth over $24 \mathrm{hr}$. These data suggest that synaptic activity stabilizes presynaptic and postsynaptic structures but that axons and dendrites respond differently when activity is blocked.

It is interesting to note that blocking glutamate receptor activity has a significantly different outcome for more complex neurons compared with simpler neurons. In complex neurons, blocking glutamate receptors leads to a net decrease in TDBL, suggesting that synaptic activity is required not only to promote branch additions and branch length extensions, as in younger neurons, but also to maintain branches that are already present at the start of the experiment. This suggests that synaptic activity can recruit 
growth-promoting mechanisms in younger neurons that may not be available for activation in more mature neurons. These data further indicate that the same pharmacological manipulation, in this case blocking glutamate receptors, can have a very different influence on dendritic morphology depending on the developmental state of the neurons. The different effects of activity blockers on dendritic development reported in the literature may have reflected the different developmental stages of neurons when the experiments were performed, not only with respect to the AMPA/NMDA ratio but also other cellular elements that jointly control morphological development.

\section{REFERENCES}

Benes F, Parks T, Rubel E (1977) Rapid dendritic atrophy following deafferentation, an EM morphometric analysis. Brain Res 122:1-13.

Blanton MG, LoTurco JJ, Kriegstein A (1990) Endogenous neurotransmitter activates $N$-methyl-D-aspartate receptors on differentiating neurons in embryonic cortex. Proc Natl Acad Sci USA 87:8027-8030.

Bodnarenko SR, Chalupa LM (1993) Stratification of ON and OFF dendrites depends on glutamate-mediated afferent activity in the developing retina. Nature 364:144-146.

Cline HT, Constantine-Paton M (1989) NMDA receptor antagonists disrupt the retinotectal topographic map. Neuron 3:413-426.

Cline HT, Debski EA, Constantine-Paton M (1987) NMDA receptor antagonist desegregates eye-specific stripes. Proc Natl Acad Sci USA 84:4342-4345.

Cline HT, Wu G-Y, Malinow R (1997) In vivo development of neuronal structure and function. Cold Spring Harb Symp Quant Biol 61: 95-104.

Constantine-Paton M, Ferrari-Eastman P (1981) Topographic and morphometric effects of bilateral embryonic eye removal on the optic tectum and nucleus isthmus of the leopard frog. J Comp Neurol 196:645-661.

Dailey ME, Smith SJ (1996) The dynamics of dendritic structure in developing hippocampal slices. J Neurosci 16:2983-2994.

Dalva MB, Ghosh A, Shatz CJ (1994) Independent control of dendritic and axonal form in the developing lateral geniculate nucleus. J Neurosci 14:3588-3602.

Deitch JS, Rubel EW (1984) Afferent influences on brain stem auditory nuclei of the chicken: time course and specificity of dendritic atrophy following deafferentation. J Comp Neurol 229:66-79.

Edwards JA, Cline HT (1997) Calcium imaging in retinal ganglion cell axon arbors. Soc Neurosci Abstr 23:604.

Feng A, Rogowski B (1980) Effects of monaural and binaural occlusion on the morphology of neurons in the medial superior olivary nucleus of the rat. Brain Res 189:530-534.

Goodman CS, Shatz CJ (1993) Developmental mechanisms that generate precise patterns of neuronal connectivity. Cell [Suppl] 72:77-98.

Goodman LA, Model PG (1990) Eliminating afferent impulse activity does not alter the dendritic branching of the amphibian mauthner cell. J Neurobiol 21:283-294.

Harris R, Woolsey T (1981) Dendritic plasticity in mouse barrel cortex following postnatal vibrissa follicle damage. J Comp Neurol 196:357-376.

Kaethner R, Stuermer C (1997) Dynamics of process formation during differentiation of tectal neurons in embryonic zebrafish. J Neurobiol 32:627-639.

Kalb RG (1994) Regulation of motor neuron dendrite growth by NMDA receptor activation. Development 120:3063-3071.

Katz L, Gilbert C, Wiesel T (1989) Local circuits and ocular dominance columns in monkey striate cortex. J Neurosci 9:1389-1399.

Katz LC, Constantine-Paton M (1988) Relationships between segregated afferents and postsynaptic neurons in the optic tectum of threeeyed frogs. J Neurosci 8:3160-3180.

Katz LC, Shatz CJ (1996) Synaptic activity and the construction of cortical circuits. Science 274:1132-1138.

Koester SE, O'Leary DDM (1992) Functional classes of cortical projection neurons develop dendritic distinctions by class-specific sculpting of an early common pattern. J Neurosci 12:1382-1393.

Kossel A, Lowel S, Bolz J (1995) Relationships between dendritic fields and functional architecture in striate cortex of normal and visually deprived cats. J Neurosci 15:3913-3926.

Kossel A, Williams C, Schweizer M, Kater S (1997) Afferent innervation influences the development of dendritic branches and spines via both activity-dependent and non-activity-dependent mechanisms. J Neurosci 17:6314-6324.
Kutsewada t, Kashiwabuchi T, Mori H, Sakimura K, Kushiya E, Araki K, Meguro H, Masaki H, Kumanishi T, Arakawa M, Mishina M (1992) Molecular diversity of the NMDA receptor channel. Nature 358:36-41.

Lankford K, Kenney A, Kocsis J (1996) Cellular mechanisms regulating neurite initiation. Prog Brain Res 108:55-81.

Lázár G (1973) The development of the optic tectum in Xenopus laevis: a golgi study. J Anat 116:347-355.

Lin S-Y, Constantine-Paton M (1998) Suppression of sprouting: an early function of NMDA receptors in the absence of AMPA/KA receptor activity. J Neurosci 18:3725-3737.

LoTurco JJ, Blanton MG, Kriegstein AR (1991) Initial expression and endogenous activation of NMDA channels in early neocortical development. J Neurosci 11:792-799.

Lund JS, Holbach SM, Chung W-W (1991) Postnatal development of thalamic recipient neurons in the monkey striate cortex. II. Influence of afferent driving on spine acquisition and dendritic growth of layer $4 c$ spiny stellate neurons. J Comp Neurol 309:129-140.

Matsumoto N, Bando T (1980) Excitatory synaptic potentials and morphological classification of tectal neurons of the frogs. Brain Res 192:39-48.

Mattson MP (1988) Neurotransmitters in the regulation of neuronal cytoarchitecture. Brain Res Rev 13:179-212.

McAllister AK, Katz LC, Lo DC (1996) Neurotrophin regulation of cortical dendritic growth requires activity. Neuron 17:1057-1064.

Monyer H, Sprengel R, Schoepfer R, Herb A, Higuchi M, Lomeli H, Burnashev N, Sakman B, Seeburg PH (1992) Heteromeric NMDA receptors: molecular and functional distinction of subtypes. Science 256:1217-1221.

Nieuwkoop PD, Faber J (1956) Normal table of Xenopus laevis (Daudin). Amsterdam: Elsevier.

O'Rourke NA, Cline HT, Fraser SE (1994) Rapid remodeling of retinal arbors in the tectum with and without blockade of synaptic transmission. Neuron 12:921-934.

Potter HD (1969) Structural characteristics of cell and fiber populations in the optic tectum of the frog (Rana catesbiana). J Comp Neurol 136:203-232.

Rajan I, Witte S, Cline HT (1998) NMDA receptor activity stabilizes presynaptic retinotectal axons and postsynaptic optic tectal cell dendrites in vivo. J Neurobiol, in press.

Rocha M, Sur M (1995) Rapid acquisition of dendritic spines by visual thalamic neurons after blockade of $N$-methyl-D-aspartate receptors. Proc Natl Acad Sci USA 92:8026-8030.

Scherer WJ, Udin SB (1989) $N$-methyl-D-aspartate antagonists prevent interaction of binocular maps in Xenopus tectum. J Neurosci 9:3837-3843.

Schmidt JT (1990) Long-term potentiation and activity-dependent retinotopic sharpening in the regenerating retinotectal projection of goldfish: common sensitive period and sensitivity to NMDA blockers. J Neurosci 10:233-246.

Schmidt JT, Buzzard M (1993) Activity-driven sharpening of the retinotectal projection in goldfish: development under stroboscopic illumination prevents sharpening. J Neurobiol 24:384-399.

Ullensvang K, Lehre KP, Storm-Mathisen J, Danbolt NC (1997) Differential developmental expression of the two rat brain glutamate transporter proteins GLAST and GLT. Eur J Neurosci 9:1646-1655.

Valverde F (1968) Structural changes in the area striata of the mouse after enucleation. Exp Brain Res 5:274-292.

Vogel MW, Prittie J (1995) Purkinje cell dendritic arbors in chick embryos following chronic treatment with an $N$-methyl-D-aspartate receptor antagonist. J Neurobiol 26:537-552.

Weisel TN, Hubel DH (1963) Effects of visual deprivation on morphology and physiology of cells in the cat's lateral geniculate body. J Neurophysiol 26:978-993.

Witte S (1995) In vivo axon arbor branch dynamics in the retinotectal system of developing Xenopus laevis. PhD thesis, University of Iowa.

Witte S, Stier H, Cline HT (1996) In vivo observations of timecourse and distribution of morphological dynamics in Xenopus retinotectal axon arbors. J Neurobiol 31:219-234.

Wong ROL, Herrman K, Shatz CJ (1991) Remodelling of retinal ganglion cell dendrites in the absence of action potential activity. J Neurobiol 22:685-697.

Wu G-Y, Cline HT (1998) Stabilization of dendritic arbor structure in vivo by CaMKII. Science 279:222-226.

Wu G-Y, Malinow R, Cline HT (1996) Maturation of a central glutamatergic synapse. Science 274:972-976.

Ziv NE, Smith SJ (1996) Evidence for a role of dendritic filopodia in synaptogenesis and spine formation. Neuron 17:91-102. 